\title{
A High-Resolution Global Climate Simulation
}

\author{
P.B. Duffy
}

January 23, 2001

U.S. Department of Energy

Lawrence

Livermore

National

Laboratory
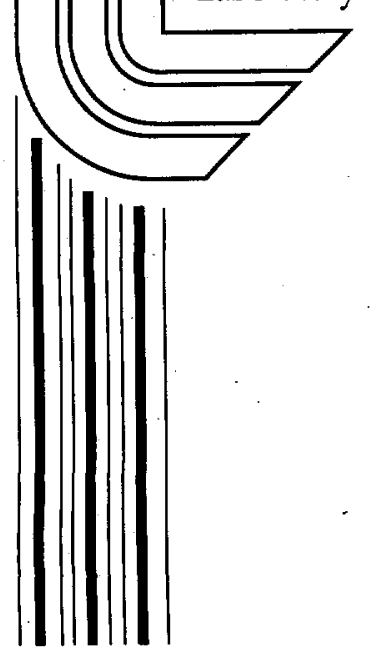

Approved for public release; further dissemination unlimited 


\section{DISCLAIMER}

This document was prepared as an account of work sponsored by an agency of the United States Government. Neither the United States Government nor the University of California nor any of their employees, makes any warranty, express or implied, or assumes any legal liability or responsibility for the accuracy, completeness, or usefulness of any information, apparatus, product, or process disclosed, or represents that its use would not infringe privately owned rights. Reference herein to any specific commercial product, process, or service by trade name, trademark, manufacturer, or otherwise, does not necessarily constitute or imply its endorsement, recommendation, or favoring by the United States Government or the University of California. The views and opinions of authors expressed herein do not necessarily state or reflect those of the United States Government or the University of California, and shall not be used for advertising or product endorsement purposes.

This work was performed under the auspices of the U. S. Department of Energy by the University of California, Lawrence Livermore National Laboratory under Contract No. W-7405-Eng-48.

This report has been reproduced directly from the best available copy.

Available electronically at http://www.doe.gov/bridge

Available for a processing fee to U.S. Department of Energy and its contractors in paper from

U.S. Department of Energy

Office of Scientific and Technical Information

P.O. Box 62

Oak Ridge, TN 37831-0062

Telephone: (865) 576-8401

Facsimile: (865) 576-5728

E-mail: reports@adonis.osti.gov

Available for the sale to the public from

U.S. Department of Commerce

National Technical Information Service

5285 Port Royal Road

Springfield, VA 22161

Telephone: (800) 553-6847

Facsimile: (703) 605-6900

E-mail: orders@ntis.fedworld.gov

Online ordering: http://www.ntis.gov/ordering.htm

OR

Lawrence Livermore National Laboratory

Technical Information Department's Digital Library

http://www.llnl.gov/tid/Library.html 


\title{
A High-Resolution Global Climate Simulation
}

\author{
P. B. Duffy, Atmospheric Science Division
}

\section{Purpose}

A major factor limiting the quality and usefulness of global climate models is the coarse spatial resolution of these models. Global climate models today are typically run at resolutions of $\sim 300 \mathrm{~km}$ (or even coarser) meaning that the smallest features represented are $300 \mathrm{~km}$ across. As Figure 1 shows, this resolution does not allow adequate representation of small or even large topographic features (e.g. the Sierra Nevada mountains). As a result of this and other problems, coarse-resolution global models do not come close to accurately simulating climate on regional spatial scales (e.g. within California). Results on continental and larger sales are much more realistic. An important consequence of this inability to simulate regional climate is that global climate model results cannot be used as the basis of assessments of potential societal impacts of climate change (e.g. effects on agriculture in the Central Valley, on management of water resources, etc.)

$300 \mathrm{~km}$ model
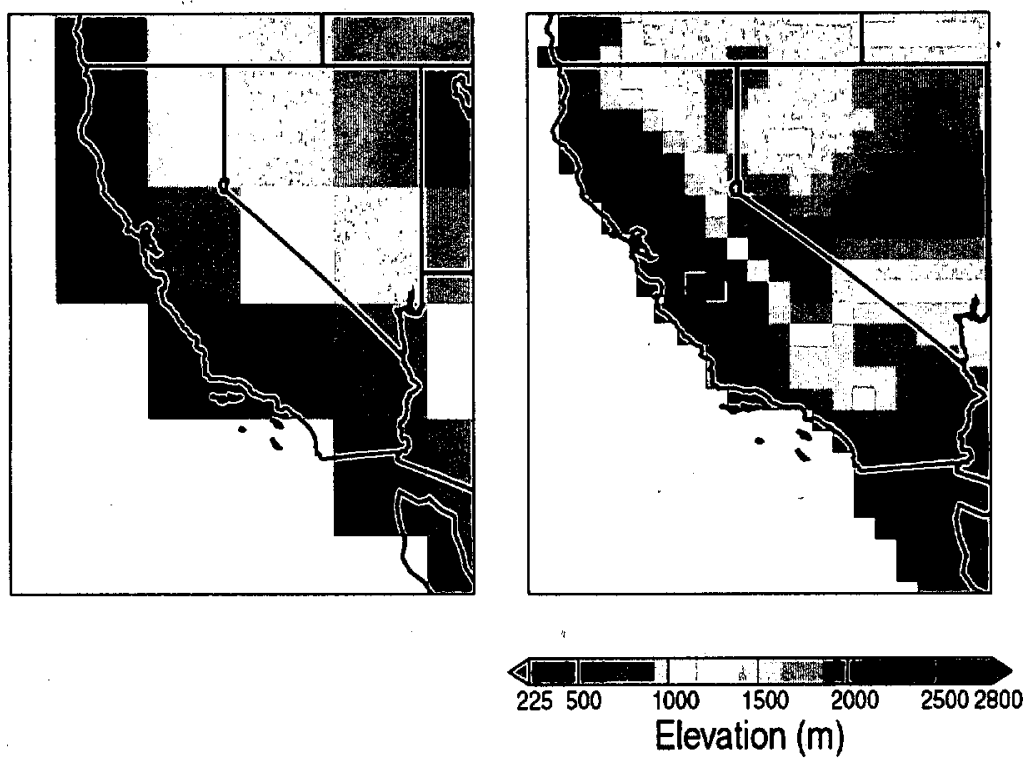

$20 \mathrm{~km}$

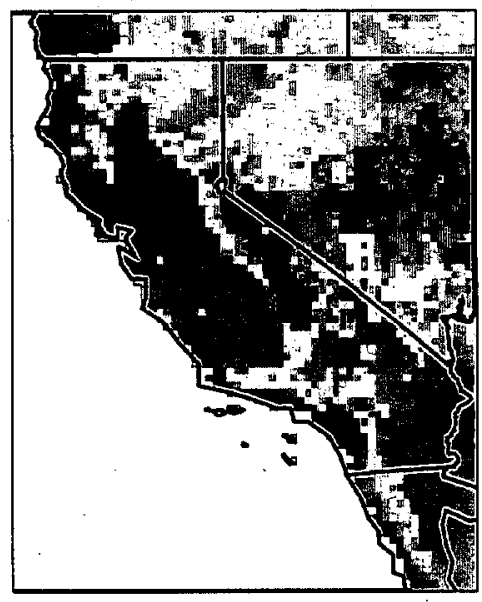

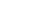

Figure 1: Surface elevations in and around California, represented at spatial resolutions of 300,50 , and $20 \mathrm{~km}$. At $300 \mathrm{~km}$ resolution, poor representation of topographic features (Central Valley, Sierra Nevada mountains, etc.) prohibits realistic simulation of California's climate. At $50 \mathrm{~km}$ resolution, basic topographic features are represented (although imperfectly), and the simulated climate is much more realistic. $20-\mathrm{km}$ resolution is desirable, but is beyond the scope of today's global models, even on an experimental basis.

One approach to simulating regional-scale climate, and the societal impacts of climate change, is to run global climate models at much finer spatial resolutions. This has not been attempted previously because the computational demands have been prohibitive. By 
taking advantage of ASCI-scale computer resources at DOE/LLNL, we have successfully performed global climate simulations at much finer spatial resolutions than ever attempted before (as fine as $\sim 50 \mathrm{~km}$ ). As expected, we found that these high-resolution simulations produce much more realistic regional climates than coarse-resolution models do. A major reason for this is better representation of topography, which strongly influences surface temperature and precipitation. We also found that the results of fineresolution simulations are superior to those of coarse-resolution simulations even on scales that are resolved in the coarse-resolution simulations (i.e., resolving fine-scale detail improves simulation of large-scale features). This result was not necessarily expected, because the model contains "parameterizations" of unresolved physics, whose behavior under a dramatic increase in resolution is difficult to predict.

\section{Activities}

We performed several high-resolution global climate simulations. For each highresolution simulation, a similar simulation at coarse resolution was also performed. The most important high-resolution simulations we performed are:

1. A simulation of the present climate at $\mathrm{T} 170$ truncation $(\sim 75 \mathrm{~km}$ resolution);

2. A simulation of the climate of 2100 at $T 170$ truncation $(\sim 75 \mathrm{~km}$ resolution);

3. A simulation of the present climate at $\mathrm{T} 239$ truncation $(\sim 50 \mathrm{~km}$ resolution).

In cooperation with colleagues at PCMDI, we have performed systematic analyses of these high-resolution simulations, comparing them to observations and to lowerresolution simulations. Figure 2 shows an example of this type of analysis, in which we compare results of a simulation at $50 \mathrm{~km}$ resolution, a simulation at $300 \mathrm{~km}$ resolution, and observations. This exercise shows that in nearly all cases the coarse-scale (> 300 $\mathrm{km}$ ) features in the fine-resolution simulation agree better with observations than the coarse-resolution model results do. 


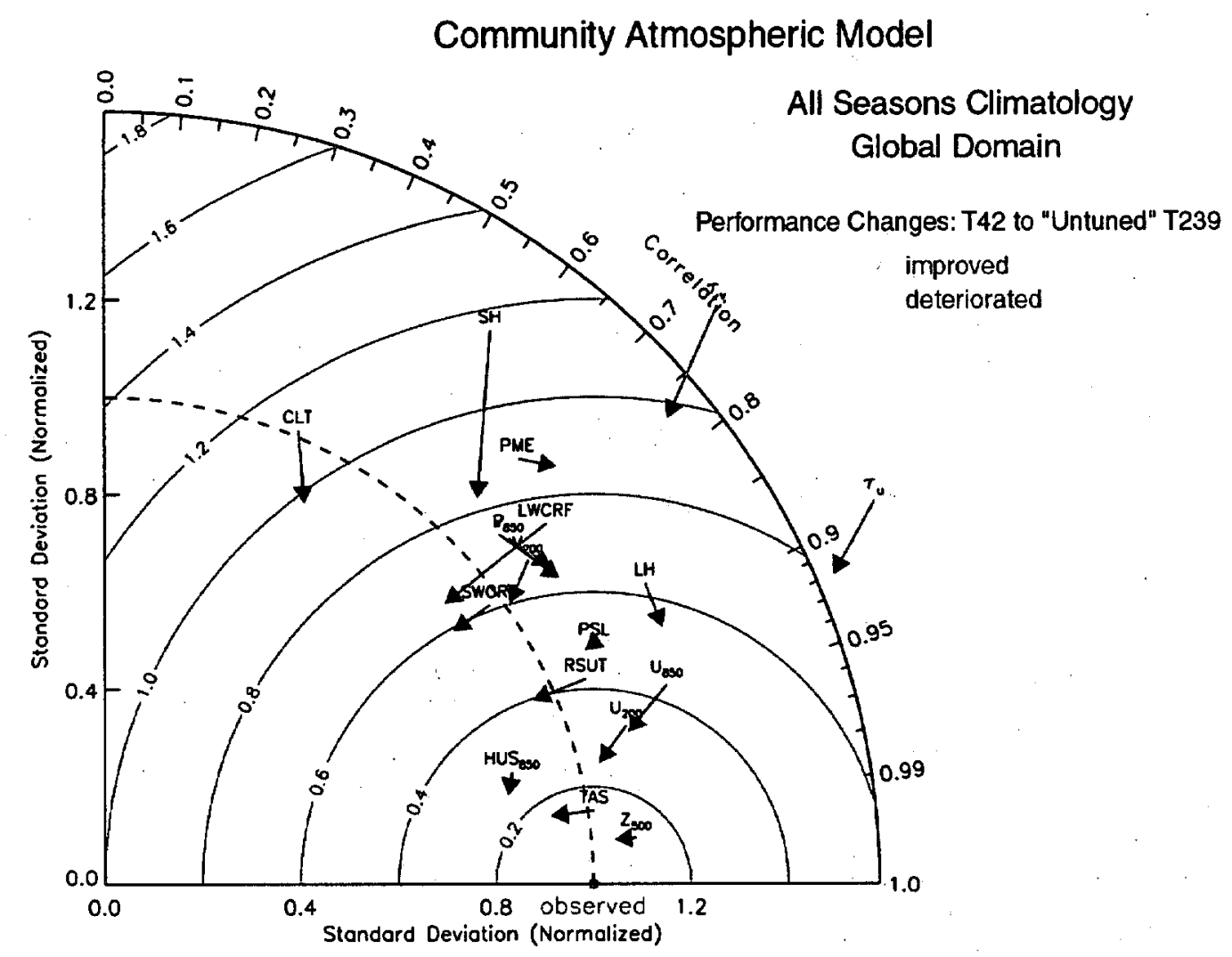

Figure 2: A "Taylor diagram" comparing results of a 300-km resolution ("T42") simulation, a 50-km ("T239") simulation, and observations. Each arrow represents a different climatic variable (CLT = cloudiness; $\mathrm{SH}=$ sensible heat flux; $\mathrm{PME}=$ precipitation minus evaporation; $\mathrm{LWCRF}=$ lonq-wave cloud radiative forcing, etc.) The radial coordinate shows the standard deviation of the model results relative to the standard deviation of the observations; the angular coordinate shows the correlation between the model results and observations. A perfect model would be plotted at $(1,1)$ (on the horizontal axis) in this coordinate system. The tail of each arrow represents the coarse-resolution (T42) model results; the head represents the fine resolution (T239) results. Arrows which point generally towards $(1,1)$ are shown in blue, and indicate that the fine-resolution results are closer to observations than the coarse-resolution results. Nearly all the arrows are blue, indicating that almost all variables are more realistically simulated at fine resolution than at coarse resolution. For this analysis the fine-resolution results have been interpolated to the coarse-resolution grid; thus this exercise assesses the realism of only the coarse-scale $(>\sim 300 \mathrm{~km})$ features in the fine-resolution results.

More accessible but less quantitative (and less comprehensive) comparisons of coarse and fine-resolution results are shown in Figures 3 and 4. In Figure 3 we show that simulated wintertime precipitation over the US agrees better with observed precipitation as the model resolution becomes finer. In Figure 4, we show that the pattern of sea level pressure (which drives the atmospheric circulation) is much closer to observations in our $75 \mathrm{~km}$ simulation of the preset climate than in a comparable $300 \mathrm{~km}$ simulation. 


\section{DJF Precipitation}

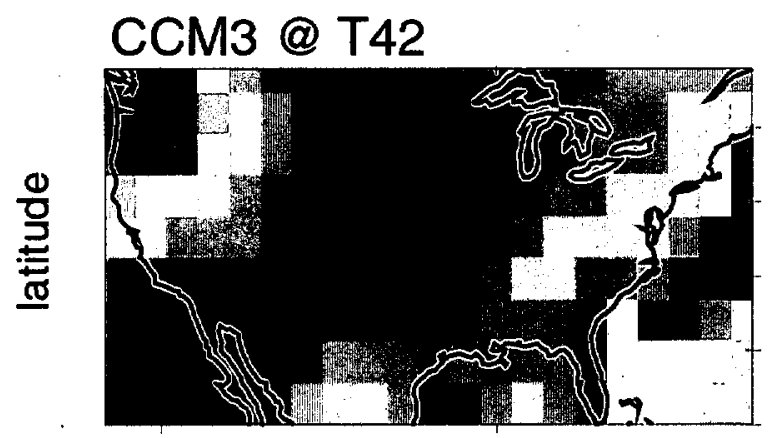

ССM3 @ T170
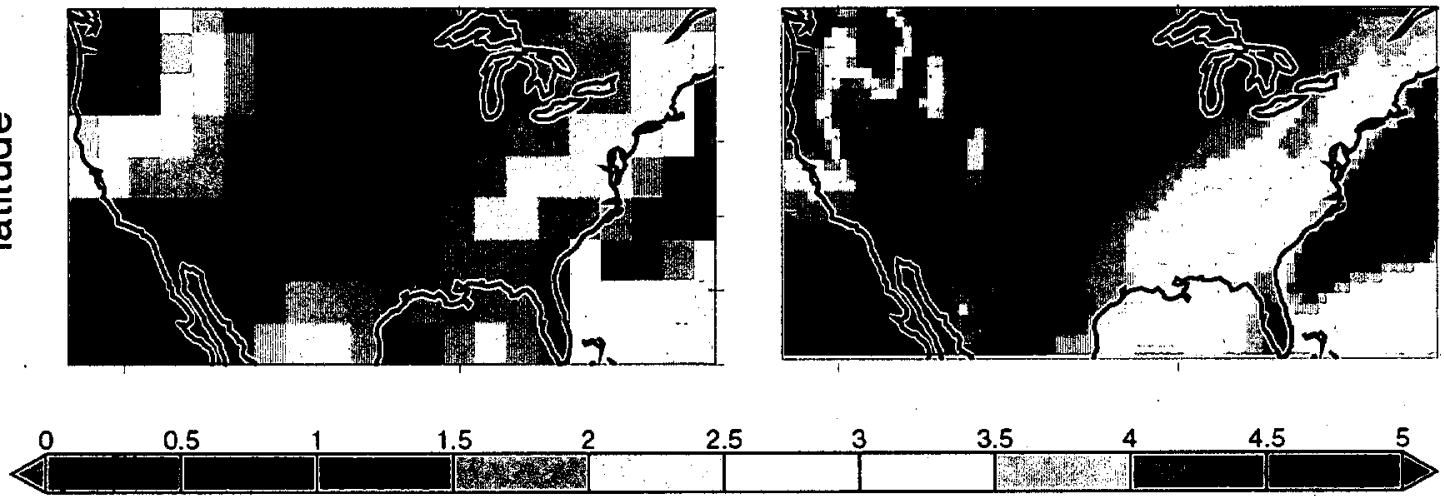

\section{ССM3 @ T239}
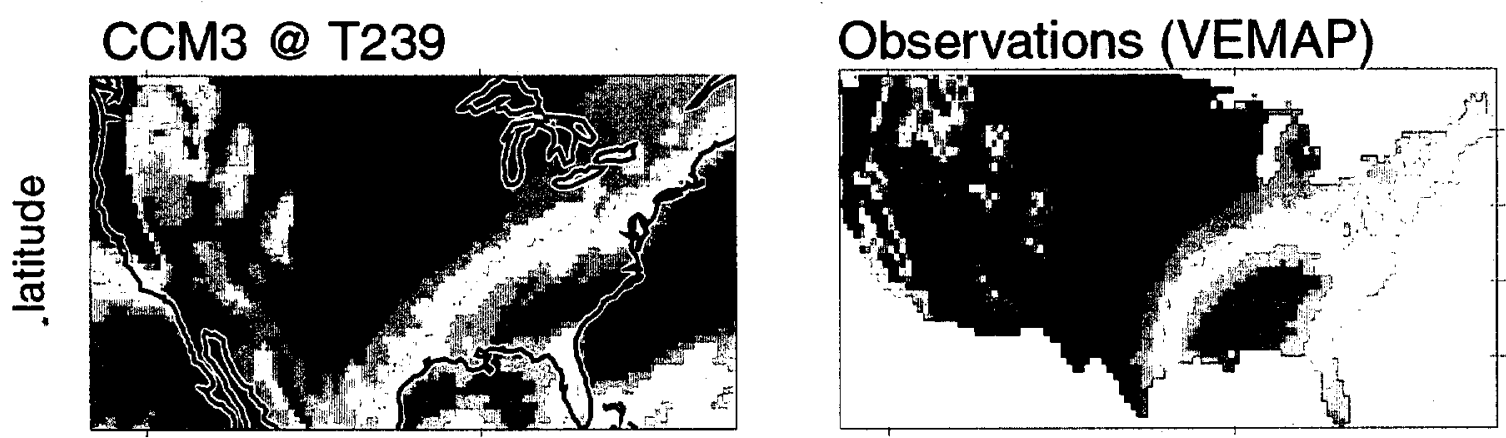

Figure 3: Wintertime precipitation over the United States as simulated in the CCM3 climate model at $300 \mathrm{~km}$ resolution (top left), $75 \mathrm{~km}$ resolution (top right), $50 \mathrm{~km}$ resolution (lower left) and in the VEMAP observational data set (lower right). The finer resolution simulations reproduce regional details in the observed precipitation pattern in the Western US, which are absent from the coarse-resolution simulation. The strong precipitation maximum observed in the Southeastern US is absent in the coarseresolution simulation, starts to appear in the $75-\mathrm{km}$ resolution simulation and is realistically represented in the $50-\mathrm{km}$ resolution simulation. 


\section{NCEP Reanalysis}
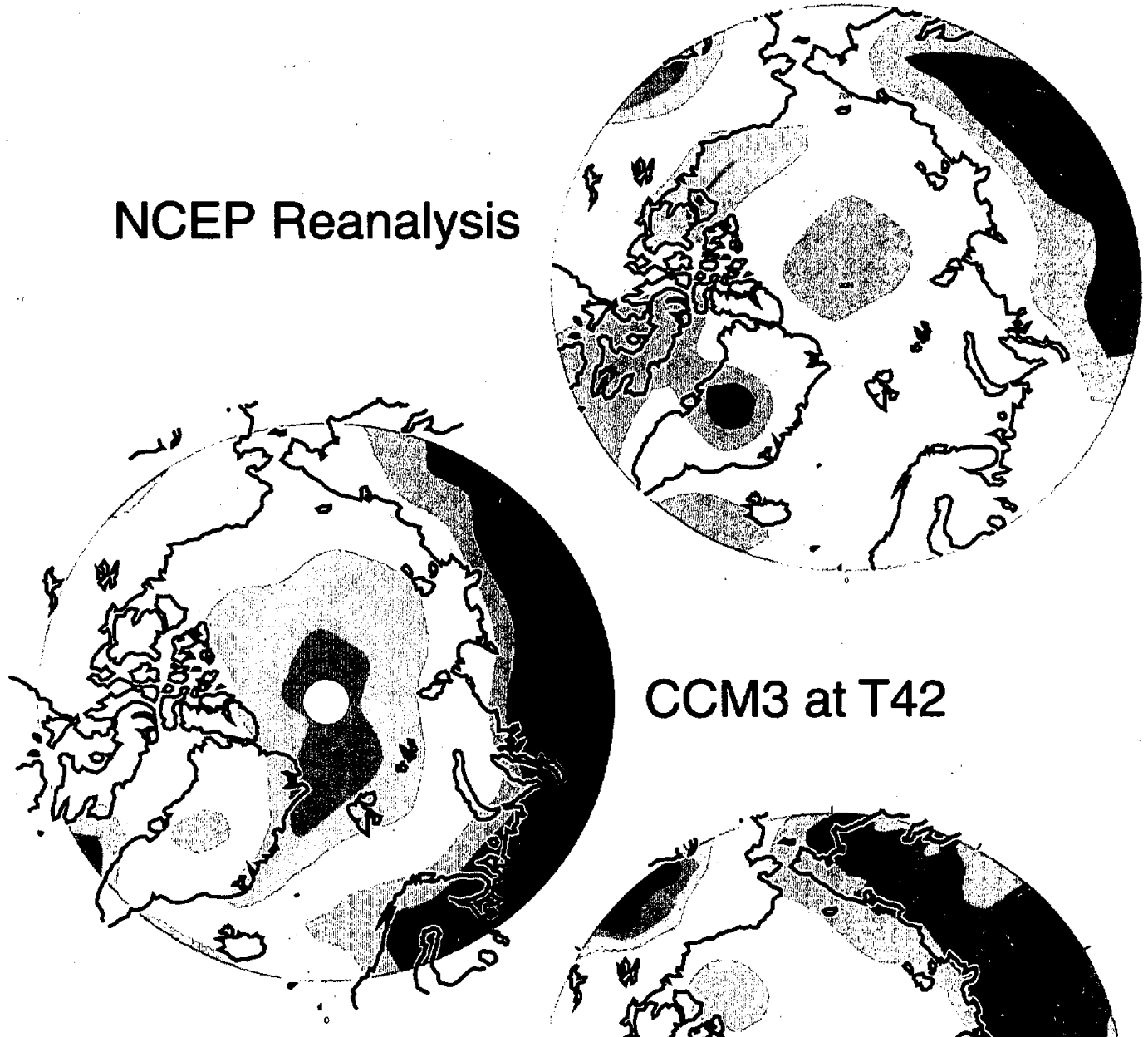

\section{$\mathrm{CCM} 3$ at T42}

$\mathrm{CCM} 3$ at $\mathrm{T} 170$
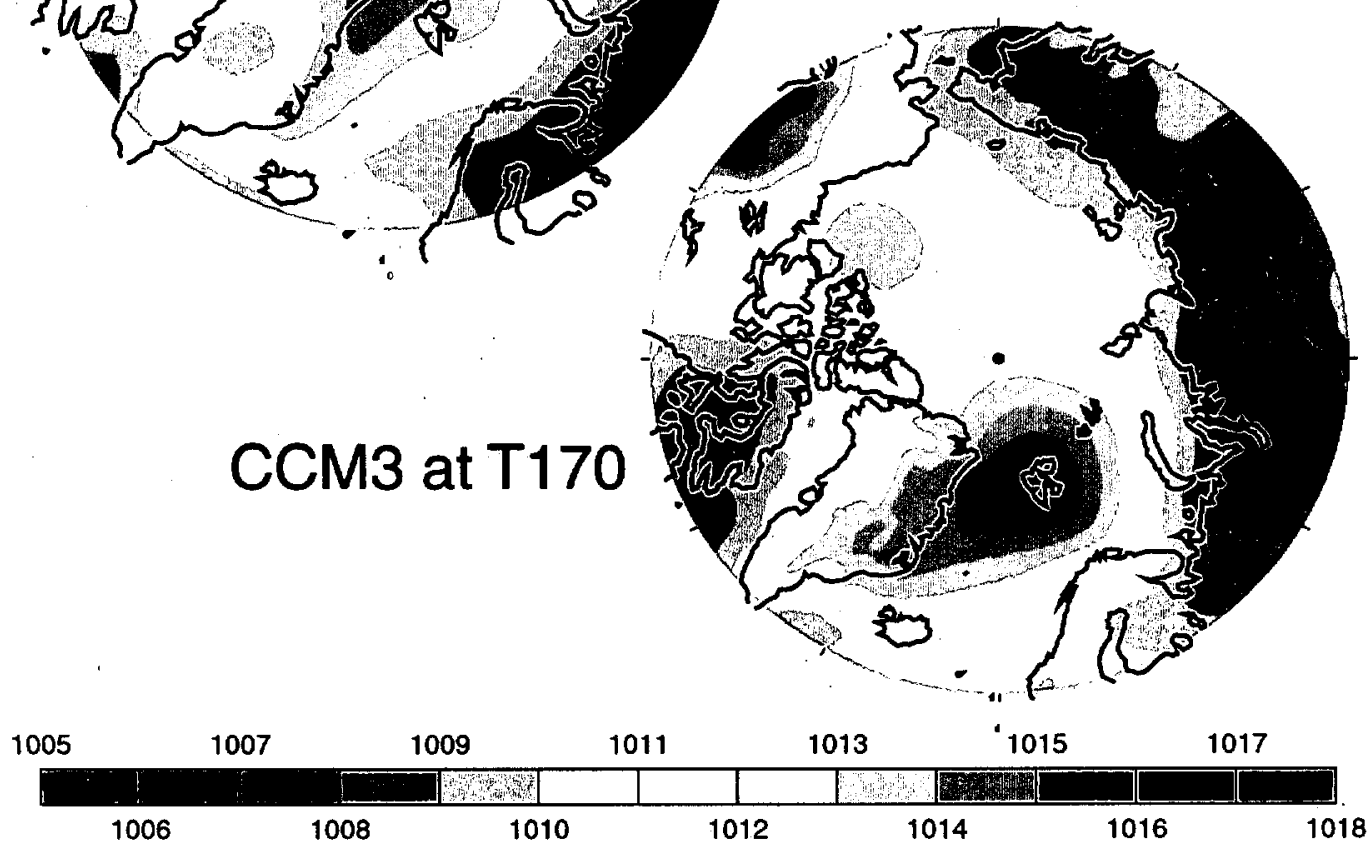

/data/ASD/pduffy/psl/psl_ncep_djf.nc

Figure 4: Patterns of sea level pressure (SLP) in the Arctic. Atmospheric winds are driven by gradients in SLP. Observations (top panel) show a Low (i.e., a pressure minimum) near the North pole, with Highs on either side. The coarse-resolution simulation (middle) has a High near the pole, resulting in wind directions which are opposite from observed. The fine-resolution simulation (bottom) agrees much more closely with observations. 
In addition to simulating the present climate at 3 spatial resolutions, we also performed simulations of the climate of 2100 (which is affected by increased atmospheric greenhouse gases) at $300-\mathrm{km}$ and $75-\mathrm{km}$ resolutions. By comparing these simulations with simulations of the present climate, we obtain predicted climate changes due to increased greenhouse gases at $300 \mathrm{~km}$ and $75 \mathrm{~km}$ resolutions. We find that global-mean predicted changes are very similar at the two resolutions (which is not surprising). However, we also find that predicted changes in specific geographical regions can be very different in the fine-resolution vs. coarse-resolution simulations. Figure 5 shows an example of this. One cannot prove that the fine-resolution results are more nearly correct, but the fact that the fine-resolution model does better at simulating the present climate makes us suspect that this is so. This underscores the need for caution in interpreting regional results in coarse-resolution climate models.

\section{Predicted DJF Temperature Change, 2100 - 2000}

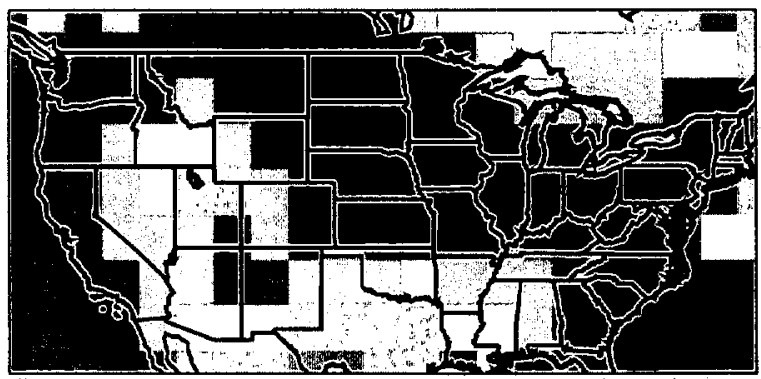

T42 ( $300 \mathrm{~km}$ resolution)
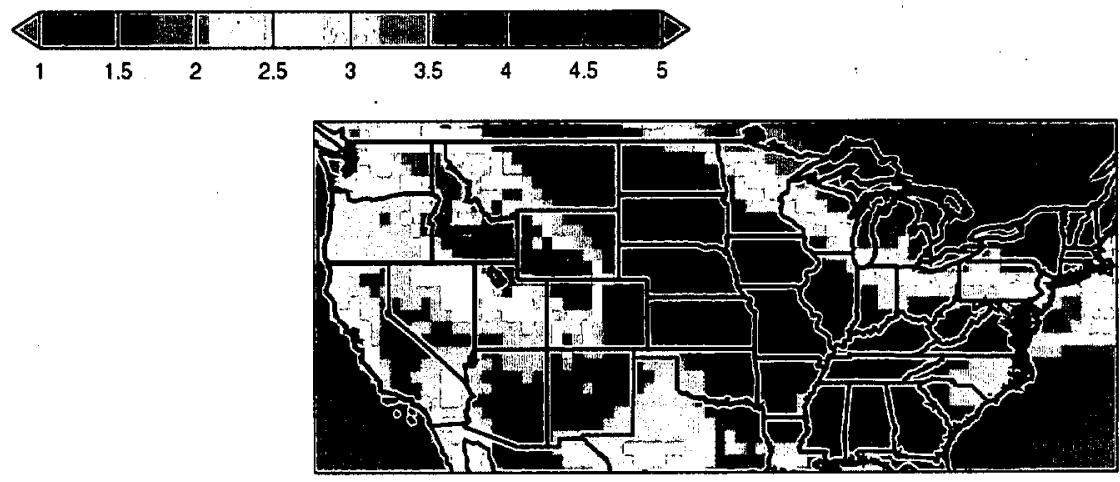

Courtesy P. Duffy, LLNL

T170 ( $75 \mathrm{~km}$ resolution)

Figure 5: Temperature changes between 2000 and 2100 due to increased atmospheric greenhouse gases, predicted by the CCM 3 model at $300 \mathrm{~km}$ resolution (top left) and by the same model at $75 \mathrm{~km}$ resolution (lower right). Predicted regional predicted temperature changes can be quite different at the two resolutions. Over the Rocky Mountains, for example, the finer resolution model predicts more warming, due to a "snow-albedo feedback" (loss of snow makes the surface darker, which amplifies warming by absorbing more sunlight). This effect is absent in the coarse-resolution model, because this model fails to simulate snow in the Rocky Mountains. This is due to 
overly smooth topography (a consequence of coarse resolution), which results in mountain regions being too low and hence too warm for snow.

\section{Technical Outcome}

Our work has produced several important results. We showed that

1. it is computationally feasible to perform short ( $\sim 10$ year) global climate simulations at resolutions as fine as $50 \mathrm{~km}$;

2. the CCM3 model physics performs well at these fine resolutions with only minor "retuning"' (parameter value adjustments).

3. our fine-resolution simulations seem to produce realistic regional-scale climates;

4. the large-scale features of today's climate are simulated more realistically when finer spatial resolution is used;

5. in simulating climate changes due to increased greenhouse gases, finer resolution produces very similar global-mean results, but regional results are often very different. 